\title{
Por uma estética radicante: deslocamento, experiência e cidade
}

PRISCYLA GOMES ${ }^{I}$

Se o tempo hoje em dia se espacializou, a forte presença da viagem e do nomadismo na arte contemporânea remete à nossa relação com a História: o universo é um território cujas dimensões são todas, tanto as temporais quanto as espaciais, passíveis de ser percorridas. A relação dos artistas contemporâneos com a história da arte se dá, hoje em dia, sob o signo do deslocamento, mediante o uso de formas nômades.

(Bourriaud, 2011b, p.123)

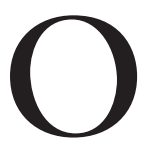
ARTISTA contemporâneo faz do deslocamento uma ferramenta de trabalho, é simultaneamente aquele que faz, traça um perfil do seu caminho, abre ou desenha uma via e adapta seu trajeto a um contexto. Ele o constrói em função dos acidentes e dos contratempos do percurso; os eventos se desenrolam e conferem ritmo à sua deambulação.

No século XIX e início do século XX, as figuras que caminham ganham novas definições. Dadaístas e pintores da nova objetividade revestiram de audácia e veemência as imagens dos caminhantes, num período em que a imagem do homem que anda replicou-se como imagem fundadora. De Rodin a Giacometti, de Joseph Beuys a Bruce Nauman, de Richard Long a Pierre Huyghe, a caminhada foi o tema escolhido para enunciar o conteúdo das produções. Caminhos distintos, mas que permitiram às práticas do percurso adquirir estatuto de arte no âmbito de suas múltiplas explorações.

Os anos 1960 e 1970 ampliaram de maneira contundente a utilização do caminhar como recurso plástico, mediante um distinto tratamento do espaço, que, naquele momento, se instalava com o próprio movimento dos artistas. Não era somente uma geometria, à qual a arte passava a se reportar, mas colocar-se em movimento era metodicamente explorado com base em uma prática nômade que emprega o deslocamento como ferramenta teórica e física. Essa cinemática prevê um novo tratamento do espaço, estabelecido não só no seio das obras, mas também no movimento realizado pelos artistas.

De alguma forma, as práticas encabeçadas por artistas do período - trabalhos que fazem do princípio do nomadismo uma prática comum, cotidiana repercutiriam fortemente nos anos 1990 e na arte contemporânea. O contexto 
urbano afirma-se na produção recente como um quadro dominante, dentro do qual o deslocamento se exprime. Diferentemente dos anos 1960 e 1970, quando os caminhantes eram sobretudo topógrafos, desbravadores de territórios e paisagens, as deambulações contemporâneas inscrevem nas cidades meandros que são fruto dos percursos dos artistas.

Os deslocamentos elegem e configuram o espaço urbano como meio, local onde se desenrolam as experiências mais diversas, das quais se captam fragmentos. Composta por multiplicidades, a cidade contemporânea é sinônimo de movimentação, mobilidade, como processo de criação artística.

Deslocar-se é, de acordo com essa concepção particular, estar sujeito ao risco da surpresa e pôr em jogo o modo de ver, abordar e se aproximar. Abrir caminho consiste em percorrer o desconhecido e se abandonar ao acaso, postura que encontra reiterações na contemporaneidade. Pôr-se em movimento, jogar-se para produzir e abrir novas possibilidades. Caminhar é o ato de traçar caminhos para dar forma à mobilidade e ao circunstancial.

Para o caminhante atual, a cidade é um território aberto que oferece suas avenidas e sua arquitetura à exploração. As práticas de mobilidade urbana tendem a se definir como uma criação em que o artista se coloca em autorrepresentação. Os corpos tornam-se o ponto de partida, o centro e o material das obras que, durante a ação, se redefinem incessantemente.

O percurso deve ser compreendido, então, não como uma tentativa de reduzir o movimento à translação, à pura e simples mobilidade, mas, ao contrário, como a base mesma do movimento, o deslocamento em sua magnitude, em todos os seus modos. Os transportes propagam-se a um certo tipo de lugar; os caminhantes deslocam-se em geografias bem particulares. Desde esse ponto de vista, a figura do turista - aquele que, no mais simples dos casos, faz um tour somente para saber como é o mundo - aparece como a ilustração mais imediata dessa expressão estética, que se tornou sinonímia de uma estética radicante.

\section{A deriva situacionista}

No contexto da década de 1960, foram os situacionistas que representaram a importante inflexão no modo de entendimento da cidade e, por consequência, nas práticas artísticas que assumiam o espaço urbano como mote de exploração através do percurso.

A cidade de Paris era vista pelos membros da Internacional Situacionista (IS), formada por escritores, arquitetos e artistas, como um contexto em que o capitalismo condicionava um desejo constante de consumo e de profunda alienação. Na sociedade do espetáculo, como a denominou Guy Debord, um dos fundadores do movimento, as relações de commodities estendiam-se a diversas áreas, inclusive à cultura, o que representava um profundo empobrecimento. Extensas críticas à sociedade moderna foram feitas a partir do veemente argumento situacionista, segundo o qual o capitalismo atuava como catalisador da corrosão social. 
Confrontar a sociedade do espetáculo e sua ideologia somente era possível, na concepção dos situacionistas, por meio de um enfrentamento de táticas em que a crítica revolucionária possibilitasse ações autônomas e expressões dissociadas da lógica do capital. A cidade passa, então, a ser concebida como lócus de uma série de práticas libertárias, tanto políticas como artísticas e chega a ser tema de investigação e de projetos utópicos.

Dentre as práticas do período, a deriva foi um conceito central encontrando desdobramentos e releituras. Uma parte representativa dos estudos que abordam o ato de andar como prática estética e instrumento de crítica ao urbanismo associa as produções artísticas contemporâneas à deriva situacionista. ${ }^{1}$ Não é que propriamente a caminhada havia até então se tornado um tema inédito nas produções artísticas, tampouco o eram a cidade e a crítica à configuração do meio urbano. Um vasto panorama histórico poderia precisar inúmeras incursões, inclusive ressaltando as investigações benjaminianas sobre a figura do flâneur e a essência da modernidade, realizadas pelas vanguardas artísticas que assumiam corriqueiramente a caminhada e as dinâmicas urbanas em representações pictóricas e fotográficas. Contudo, essas incursões detinham-se essencialmente em representações da caminhada e deslocamentos, o que levaria grupos como a Internacional Situacionista (IS), o Fluxus ${ }^{2}$ e Arte Conceitual a abandonar os meios tradicionais de apreensão do espaço urbano e da caminhada, assumindo a ação como objeto de sua investigação per si.

No texto-manifesto a Teoria da deriva (1958), Guy Debord inaugura o conceito cuja prática viria a ser recorrente como estratégia criativa nas produções artísticas posteriores. De caráter principalmente urbano, a prática "consiste em perambular, sobretudo a pé, sem rumo predefinido, escolhendo ao acaso, ou com base em sensações e impressões extemporâneas, a direção a ser tomada a cada momento" (Visconti, 2014, p.7). Realizando uma releitura do flâneur e dos happenings dadaístas ao contexto das caminhadas parisienses, a deriva encontrou adeptos não apenas em artistas simpáticos aos ideais sociopolíticos da Internacional Situacionista, como também nos menos radicais, estabelecendo, assim, já nos anos 1960, uma vertente de adaptação e releitura do conceito. O perder-se pela cidade era reconhecido como uma possibilidade expressiva concreta de antiarte ${ }^{3}$ e assumia-se essa prática como meio estético-político para subverter o sistema capitalista do pós-guerra sob o anseio de uma arte não comercializável. Derivar era um modo de se afastar da vida burguesa e de rechaçar as regras do sistema da arte. A deriva consistia numa ação fugaz, um instante imediato para ser vivido no presente, sem ter como foco principal sua representação e conservação no tempo.

As referências aos escritos situacionistas comportam sempre uma ambiguidade peculiar, uma vez que as propostas e discussões oscilam entre um engajamento em ações pautadas pelo desejo de revolução política, e uma concepção lúdica de enfrentamento das cidades e da sociedade. Na deriva urbana, 
traçavam-se a utopia situacionista de liberdade e reconstrução da vida cotidiana e também os primórdios de uma revolução cultural.

Contudo a vinculação com o espontâneo e com o acaso era pouco defendida por Debord, que afirmava ser a dimensão aleatória menos importante do que parecia, reforçando a associação da deriva ao reconhecimento do caráter psicogeográfico $^{4}$ das cidades. Para ele, à medida que o sujeito derivava e mapeava alguns aspectos de seu entorno, o efeito do acaso na eleição dos percursos tendia a se reduzir. Essa relativização da importância do acaso nessas ações marcava uma crítica às deambulações surrealistas e simultaneamente um distanciamento delas, pelo seu excesso de confiança no fortuito. Debord defendia uma atuação consciente e metódica diante o contexto social, questionando e criticando o desprezo do anarquismo pelo método. Sua concepção era a de que o curso natural dos acontecimentos desembocaria na própria revolução popular. Ao contrário de seus antecessores, a deriva estava submetida a regras e a metodologia claras, dependendo das características psicogeográficas do ambiente a explorar. A racionalidade inerente à sua metodologia excluía o caráter inconsciente das deambulações e da dita embriaguez que acometia o flâneur. Tratava-se de um método que tinha a própria cotidianidade como campo de ação e, como mote, um caráter totalmente consciente de suas apreensões. Era necessário atuar ao invés de sonhar (Careri, 2013, p.94), construir situações fugazes, porém conscientes.

Nos primeiros anos da IS, durante os quais se deu muita ênfase ao modo como as futuras cidades deveriam ser construídas, a deriva foi um meio de descobrir quais bairros deveriam ser preservados. As práticas de deriva ganhavam especial importância diante daquilo que seus adeptos definiam como planejamento urbano excessivamente racional e frio, de influência maciça, particularmente na Europa pós-guerra. Eles reagiam à cultura burguesa e à política, de um lado, e ao funcionalismo estéril e austero do modernismo arquitetônico, de outro.

Os situacionistas perceberam que a paisagem, principalmente urbana, vinha sendo alterada e defendiam a pesquisa psicogeográfica como um meio de revelar e combater essa alteração. De acordo com a teoria debordiana, uma série de instruções determinava a duração do percurso, as localidades possíveis para o início e a quantidade de participantes, quase a direcionar a deriva a uma espécie de laboratório de registro e vivência urbanos.

O mapeamento possibilitado pela deriva era tido como meio primordial à produção de uma arte total. Os situacionistas reconheciam no urbanismo a expressão de uma arte que instituía a criação de um novo meio ambiente, configurado pelos seus habitantes que ditavam suas necessidades no convívio e no reconhecimento desse espaço. Esse reconhecimento decorreria da associação e da interferência formal de outras artes que assistiam à concepção dessa arte total. Cabe frisar que tanto a deriva quanto outras teorias situacionistas deixaram muito mais um legado do que obras propriamente ditas. A tentativa de fundir 
arte e vida não se baseava na intenção de deixar provas materiais das ações, mas de promover mudanças nas formas como os indivíduos interagiam e pensavam sobre as estruturas que governavam suas vidas.

\section{Derivações e apropriações da deriva: Nicolas Bourriaud e a arte radicante}

A “conversão” do percurso à condição de prática artística engloba um conjunto de terminologias que, embora não sinonímicas, contribuem para qualificar as incursões espaciais do caminhante em períodos distintos da história da arte e do urbanismo. A mais recente delas, forma-trajeto, cunhada pelo filósofo e curador francês Nicolas Bourriaud no livro intitulado Radicante (publicado após sua curadoria da Tate Britain Triennal 2009), lança a hipótese de não se tratar somente de uma nova terminologia, tampouco de uma nova tendência na arte, mas de uma expressão primordial do que viria ser uma estética contemporânea. Cabe frisar que os paradigmas de Bourriaud envolvem uma série de adaptações e releituras da teoria e da história da IS. Ora mencionados diretamente, como em Formas de vida (Bourriaud, 2011a), ora omitidos, como em Radicante (Bourriaud, 2011b), os preceitos e as práticas desse grupo evidenciam haver uma relação direta entre deriva e forma-trajeto.

Partindo da premissa de que “andar a pé não é remunerador”, Bourriaud apresenta sua hipótese: os deslocamentos do artista moderno e as experiências situacionistas prenunciavam uma atitude contestadora e não submetiam o tempo à produtividade cronometrada da lógica industrial. Para ele, a arte contemporânea derivaria antes do dandismo do que de Goya e Turner.

Bourriaud afirma que alguns gestos, relatos e modos de existência lhe parecem dignos da mesma atenção que uma escultura ou quadro. A vida cotidiana, assumida como produtora de obras de arte, foi um viés importante para aproximar essas produções da contemporaneidade. O deslocamento constitutivo, aquele no qual o grupo/indivíduo percorria o espaço urbano a reconhecê -lo (de que se tratou a deriva situacionista) torna-se, na concepção de Bourriaud, um método de representação. O autor defende que, quando obras de arte oriundas de trajetos são exibidas, elas oferecem ao público "uma visão positiva do caos e da complexidade", uma "experiência positiva de desorientação" (Bourriaud, 2011a, p.13).

Bourriaud assume que Debord via a arte como um mero reservatório de exemplos do que deveria ser tangível e alcançado no cotidiano. A crítica aos situacionistas, porém, não se direcionava propriamente a um descontentamento com a produção artística, mas à constatação de que a arte passava por um total esvaziamento ideológico. Estes propunham que a produção artística deveria ser coletiva e, por não acreditarem que as obras de arte fossem capazes de promover uma mobilização coletiva, não enxergavam qualquer conquista social possível. A arte deveria ser resultado de uma revolução social e política e, numa sociedade sem classes, não haveria a categoria artista. Os situacionistas primavam pelo ideal 
de que a figura do "mestre" inexistia e priorizavam o ativismo em detrimento da criação artística.

Um dos principais diferenciais, portanto, entre as teorias de Bourriaud e da IS se dará pela apologia à convivialidade. A explanação de Bourriaud, nas últimas décadas, tem articulado a relação entre trabalho artístico e contexto relacional, focado em momentos de sociabilidade. $\mathrm{O}$ termo relacional não aparece ao acaso e, embora evitado pelo autor ao discorrer sobre sua estética radicante, remonta a uma de suas obras embrionárias, cujas bases encontram desdobramentos em suas defesas posteriores: a estética relacional.

Formulada em 1996, a estética relacional tematiza explicitamente a relação entre arte e espectador. Bourriaud descreve o trabalho de artistas como Rikrit Tiravanija, Philippe Parreno, Maurizio Cattelan, Dominique Gonzalez-Foerster, Douglas Gordon, Pierre Huyghe, entre outros. As obras desses artistas encarnam uma dicotomia moderna: existem apenas como performances em determinados tempos e lugares, embora sejam reprodutíveis como ações.

Essas situações "construídas" nublam a linha divisória entre participante, trabalho, artista e espectador e levantam questões sobre a nossa organização social. Em certo sentido, a arte sempre foi feita para propor questionamentos sobre as relações sociais, e Bourriaud meramente aponta os contextos socioeconômicos e as formas como nossas relações sociais foram afetadas pelas novas tecnologias. Nessa perspectiva, a globalização teria surgido não só como um índice da cada vez mais frequente circulação cultural, emulando o modus operandi da economia, mas também como direcionador das tendências artísticas dominantes nos centros de poder econômico. Trata-se de uma forma de proceder em que o referente determina as relações que se estabelecem, de uma nova compreensão da estética, baseada na urbanidade e na interatividade e enraizada no mundo material e nas realidades históricas, bem como nas condições sociais.

Com a estética relacional, Bourriaud postula uma estética para o mundo contemporâneo, uma estética que reflita as mudanças ocorridas nas sociedades capitalistas pós-industrializadas. Para Bourriaud, isso exige incorporar novos conceitos teóricos e, particularmente, os modos como eles se relacionam com a tecnologia: usabilidade, interatividade, acionamento, volta, ida para frente e para trás, e assim por diante. Resumindo, com a estética relacional ele afirma que os artistas contemporâneos - ou, pelo menos, aqueles que trabalhavam na década de 1990 - rejeitam noções tradicionais de estética em favor de um trabalho que joga com as relações sociais. Daí a arte tornar-se mais reprodutibilidade e desempenho e menos objetos e posteridade, concentrando-se na "documentação". Ele reitera que a arte contemporânea é "visível apenas em um momento específico" e que a documentação não deve ser confundida com o trabalho em si. Esse tipo de atividade pressupõe um contrato com o espectador, um "arranjo" cujas cláusulas tenderam a se tornar diversificadas desde os anos 1960 (Bourriaud, 2009a, p.29). 
Defendendo a arte relacional como alternativa ao modelo capitalista, a proposta tinha um forte apelo baseado na inserção de formas conviviais nas exposições, reafirmando uma faceta da produção artística centrada na improvisação e no cotidiano e questionando a representatividade do cubo branco no processo de validação dos trabalhos. Essa estética, temporariamente dissociada do espaço institucional, encontrava fortes implicações no espaço público. Não obstante, críticos, como Claire Bishop, alegam que a estética relacional teria, na verdade, contribuído para a institucionalização da arte participativa.

As observações de Bishop à arte relacional de Bourriaud encontram ressonâncias na análise de sua concepção de estética radicante. É possível identificar artifícios similares na elaboração dos dois termos, seja pela tentativa de localizar o domínio da arte radicante em uma nova ordem socioeconômica e política, seja por afirmar seu ineditismo, ignorando similaridades entre ambos e experiências e contextos anteriores. Outra implicação importante é como essas estéticas, apesar de apresentadas com um caráter de contestação e guerrilha da produção contemporânea, contribuem para a sua institucionalização e formatação. Isso posto, será possível delimitar algumas especificidades da arte radicante, esse novo regime estético que Bourriaud relaciona irrestritamente ao deslocamento.

\section{A forma-trajeto: deslocamentos na cultura contemporânea}

Durante suas investigações sobre a natureza da arte contemporânea, Nicolas Bourriaud usualmente se vale da noção de arte global, marcada por contexto de proliferação das trocas e pela intensificação de fluxos. A cultura contemporânea estaria pautada por negociações globais e descentralizadas, intermediadas por discussões entre participantes das mais diferentes culturas. Uma cultura que, segundo Bourriaud, deve ser não somente plural, mas poliglota, orientada à tradução, de modo que o imigrante, o exilado, o turista e o andarilho urbano possam se comunicar livremente.

A intensificação dos fluxos migratórios e financeiros, a emigração, o adensamento das redes de transporte e a eclosão do turismo de massa têm esboçado novas culturas transnacionais típicas não mais como desdobramentos de uma pós-modernidade, mas da altermodernidade. A altermodernidade teria como função primordial, diante desse cenário, assumir a diversidade como categoria de pensamento e a tradução como meio de preservar traços identitários. Os criadores contemporâneos viriam, assim, assentando bases para uma nova estética, oriunda de uma arte radicante que, pelo próprio termo, remonta a um organismo capaz de fazer brotar suas próprias raízes e agregá-las à medida que avança. Em termos gerais, as práticas errantes de hoje adquirem importância crucial, responsáveis que são por fornecer à arte um modelo de composição mas conferir à noção de território e a leitura do traçado urbano uma nova dimensão.

A viagem (e o deslocamento) não é, portanto, um mero tema da moda, e sim um signo de uma evolução mais profunda, que afeta as representações do mundo em que vivemos e nosso modo de habitá-lo, concreta ou sim- 
bolicamente. O artista tornou-se o protótipo do viajante contemporâneo, o Homo viator, cuja passagem através dos signos e formatos remete a uma experiência contemporânea da mobilidade, do deslocamento, da travessia. [...] O surgimento do trajeto como princípio de composição tem sua fonte em um conjunto de fatos ligados a uma sociologia de nosso ambiente visual: a globalização, a banalização do turismo, assim como a irrupção da tela do computador na vida cotidiana $[. .$.$] com a explosão da internet. (Bour-$ riaud, 2011b, p.115)

Os exemplos são inúmeros. Gabriel Orozco, Thomas Hirschhorn, Doug Aitken, Francis Alÿs são alguns dos artistas que expressam o aspecto errante da vida urbana contemporânea, que não se reduz somente às cidades e está em todos os continentes.

O autor propõe um modelo de como a arte contemporânea se espraia pelos sistemas culturais mundiais e como essa circulação encontraria desdobramentos compositivos e formais com implicações conceituais e filosóficas.

O “artista radicante" é tomado pelo autor como sintoma de um mundo marcado pela mobilidade resultante da porosidade das fronteiras entre estados nacionais; das migrações; do turismo crescente; dos fluxos econômico-financeiros acelerados; ou das navegações pela internet. A figura emblemática de nossa "era precária” é, assim, na convicção de Bourriaud, a "viagem", ou "errância”. (Fabbrini, 2012)

A errância, para Bourriaud, representa uma interrogação política da cidade. É a escritura em marcha e é a crítica do urbano, considerado matriz dos cenários habitados. A errância funda uma estética do deslocamento.

$\mathrm{O}$ que ressalta dessa proliferação de projetos nômades ou expedicionários na arte contemporânea é a insistência no deslocamento: em face das representações congeladas do saber, os artistas acionam esse saber construindo mecânicas cognitivas produtoras de distanciamento, de afastamento em relação às disciplinas instituídas e de colocações em movimento de conhecimento. (Bourriaud, 2011b, p.113)

Um aspecto determinante a esse artista radicante é que a noção de deslocamento está muito além dos contornos metropolitanos. Novas ambiências surgem do advento do digital, que condiciona também uma nova forma de percepção estreitamente vinculada a uma escala global de fluxos e de inúmeras facilitações ao deslocamento e à viagem.

Alguns espaços nos quais o artista se desloca já não estão mais associados somente à sua corporalidade ou limitados a um contexto. $\mathrm{O}$ advento do digital também condiciona as andanças digitais. Nelas, os acessos não são lineares, nem metódicos e emulam uma distinta noção da fronteira entre público e privado.

Pertencente à altermodernidade, esse artista radicante é parte de um "projeto de construção que permitiria novos direcionamentos interculturais, a construção de um espaço de negociação [...] não mais ligado antes à origem 
dos discursos e formas do que à sua dinâmica" (Borriaud, 2011b, p.35). Para concretizar esse projeto é imprescindível um novo sujeito, um homem sem aura - Bourriaud retoma Walter Benjamin e as noções de aura e autoria. Um sujeito "libertado dessa aura psicológica representada pela sacrossanta identidade", que pudesse se "mover nas culturas sem se identificar, criar nelas singularidades sem nelas imergir, surfar nas formas sem penetrá-las" (ibidem, p.40).

O artista caminhante é uma representação simbólica da modernidade e a personificação da urbanidade contemporânea. Ele extrai significados da cidade e acrescenta significados ao espaço. "A partir de uma realidade sociológica e histórica - a da era dos fluxos migratórios, do nomadismo planetário, da mundialização dos fluxos financeiros e comerciais -, esboça-se um novo estilo de vida e de pensamento" (ibidem, p.52). Esse sujeito caracterizado por Bourriaud como um andarilho cria uma nova topologia do mundo através de uma compreensão alterada do espaço e do tempo, com a ajuda da viagem e de uma iconografia da mobilidade. Inserido nessa topologia, o artista funciona segundo as dinâmicas de um modo de pensamento baseado na tradução - "essa modernidade do século XXI é tradutora" (ibidem, p.55) -, que medeia os elementos da cultura global.

Submetida à lógica global, a arte contemporânea não apenas se afirma pelo contexto em que estão inseridos seus artistas, mas ela mesma se configura como uma rede de eventos que alimentam sua produção. Parece haver uma certa inversão de papéis nessa arte global, em que temas não são elencados e definidos pelo contexto no qual se inserem e pelos questionamentos de seus artistas. Um circuito internacional de feiras, bienais, exposições em importantes museus e galerias de arte ganha escala; curadores e colecionadores escolhem artistas que respondam com novas obras aos questionamentos e aos temas explicitados nas exposições. Muitas vezes pautados por temas politicamente urgentes, os curadores definem seus escopos de mostras e trabalhos regidos por uma encomenda, às vezes, crivados como uma ilustração superficial de uma teoria. Em sua teoria crítica, Bourriaud discute algumas implicações similares, que colocam em situação contraditória o artista contemporâneo semionauta, como ele o define.

A crítica de Bourriaud aos situacionistas e principalmente ao modernismo centra-se na política de imposições de normas e no radicalismo na forma. Em algumas passagens, como evidencia Owen Hatherley, as alternativas contemporâneas de Bourriaud assemelham-se a uma versão despolitizada da Internacional Situacionista, principalmente pela des-historização com que o autor aborda seus intentos. Ele agrupa uma série de produções sob categorias que ignoram diferenças processuais e aspectos sociais, e está sempre atento a elementos compositivos.

Já evidenciando apreço pela representação, logo no início de seu Radicante, Bourriaud (2011b) questiona os porquês de a globalização quase nunca possuir uma abordagem de perspectiva estética e pergunta sobre como esta últi- 
ma afetaria a natureza das formas. Apresenta, então, o seu conceito de radicante relacionado a figuras dominantes da cultura contemporânea - o imigrante, o exilado, o turista e o andarilho urbano -, que assumiriam uma postura extremamente distinta do radicalismo arraigado do modernismo ou do enraizamento distorcido, característico do pós-modernismo.

Se a emergência do flâneur coincidiu com um processo de mudança na história moderna, pautada pela industrialização e pelo capitalismo modernos, a transposição para o contexto contemporâneo define um andarilho, sobre quem os efeitos da tecnologia e da comunicação não podem ser descartados.

$\mathrm{O}$ artista caminhante é produto da cidade e de seus autores, na medida em que a experiência nos seus modos mais ordinários, estritamente relacionados a um processo de alienação, em parte, como resultado do processo de desengajamento da sociabilidade e perda da conexão com a cidade. Uma preocupação que estava presente já no discurso da IS, no final da década de 1960, a mudança do foco social da produção para o consumo veio a se tornar o significado primordial da vida urbana. $\mathrm{O}$ andarilho contemporâneo está à mercê do espetáculo e se vê afetado por uma intensa penetração da mídia em seu cotidiano. É aí que parece esvair-se a sua apologia à liberdade do sujeito e do potencial contestador da produção artística radicante. Artistas em conformidade com a precariedade fundamentada pela sociedade capitalista não são de modo algum livres conceitual ou formalmente. A comparação entre nômades, exilados e artistas parece desconsiderar não apenas o sistema da arte, com sua elitização, mas também a condição de efetiva precariedade que assola grande parte da ordem socioeconômica global. Há em sua proposição, em última instância, uma homogeneização da precariedade, que integraria o artista, o curador, o político, o investidor e os migrantes, fruto da carência de oportunidades no contexto do capital. Uma homogeneização que relativiza e, por que não dizer, compromete o caráter político de sua estética baseada na arte como forma social.

Assim como "relações" na estética relacional, a precariedade, a transitoriedade e a urbanidade são noções suficientemente amplas para admitirem tais contradições. Os exemplos de artistas, mencionados pelo autor, não parecem mais que subsídio a suas constatações, em vez de propriamente uma análise atenta de suas multiplicidades. Se o pensamento estético pós-moderno lhe parecia distorcido por uma série de predeterminações - seja de proveniência, seja por um pensamento crítico predominante - que acabavam ordenando as produções "como ovos em uma linha de produção" (Bourriaud, 201 lb), o sujeito contemporâneo, o artista radicante, parece não ter sua definição e atuação tão dissociadas dessa normatização.

A queixa de Bourriaud (2011b), logo no início de Radicante, sobre a urgência do assunto relativo à forma, comprova-se conivente com a priorização dada a ela pelo artista, seja em seu posicionamento seja em sua pesquisa. Seria necessária, para comprovação de seu argumento, uma seleção condizente que 
neutralizasse certas distorções - como a apropriação desistoricizada de alguns termos e práticas anteriores. Seu apreço pela forma, já presente na leitura que faz da deriva situacionista, sobrepõe-se ao próprio trajeto e à experiência de transformação daquele que caminha. Há claramente uma lógica de acúmulo, seja de exemplificações de artistas que tratam do trajeto, seja da apropriação e da ressignificação de termos. Fazendo jus a toda a sua explanação acerca da tradução, que transporta o objeto de que se apodera e vai ao encontro do outro para apresentá-lo de uma forma familiar, Bourriaud traduz e relê uma série de conceitos (hibridação cultural, pós-história, pós-modernidade) a fim de relativizá-los intencionalmente, em prol de sua estética radicante. Há uma série de dimensões do deslocamento que o teórico equivale, a fim de afirmar a estética radicante como uma unidade. Na concepção desta estética, equivalem-se a caminhada, o êxodo, a migração e a viagem, pouco esmiuçando suas especificidades. Difícil, com tamanhas relativizações, afirmá-la como ponto nevrálgico na produção contemporânea. Suas comparações e relativizações parecem provar que o argumento do livro é uma metáfora que coloca as poéticas a seu serviço, e não o contrário.

\section{Considerações finais}

Os últimos anos têm marcado uma transformação nas atividades de artistas e curadores com a intensificação do deslocamento como prática recorrente da profissão. A necessidade de fazer-se presente e a par de pautas decorrentes de distintos contextos sociais e políticos vem conduzindo esses profissionais a se inserirem num sistema de arte que privilegia a mobilidade como gesto da contemporaneidade.

O deslocamento é o paradigma do curador contemporâneo que percorre exposições e congressos por todo o mundo e, principalmente, é o paradigma do artista para o qual deslocar-se tornou sinônimo de estar em diálogo, atualizado e, em igual medida, de atuar em diferentes residências artísticas que impulsionam sua inserção no circuito.

Obviamente, a noção de deslocamento, quando pensada nos motes acima descritos, aproxima duas práticas: a viagem e a deriva. Essa diferenciação muitas vezes não é expressa de maneira tão clara por teóricos que estudam o deslocamento como prática artística, a citar como exemplo a abordagem analisada de Nicolas Bourriaud. Evidente que, mesmo com especificidades muito distintas, é o âmbito do movimento que torna essas duas práticas parte de uma base comum.

A intensificação do deslocamento como prática recorrente no sistema das artes abre hipóteses que justificam, ou pelo menos sugerem possíveis motivos à crescente abordagem da mobilidade e, por consequência, da caminhada como prática artística em trabalhos e exposições, intensificando a problematização dos contextos urbanos aos quais pertencem os artistas que neles se detém. Porém, embora os dados comprovem a relevância da abordagem, a análise das concep- 
ções de Nicolas Bourriaud contextualiza, porém exclui uma dimensão determinante às essas práticas artísticas: a tradução da experiência do indivíduo que caminha e o potencial transformador da caminhada ao agente do percurso.

Por outro lado, a documentação é uma importante entrada à reflexão acerca do relato que essas ações circunscrevem. O relato desses percursos é bastante detalhado, muitas vezes cumpre um papel institucional estritamente ligado a forma como serão expostos e, parecem confrontar-se com a efemeridade e casualidade do gesto.

Diferentes performances deixam vestígios de sua existência, apostando na coleta desses fragmentos como possibilidade de construção de um histórico de seus atos. Trata-se de trabalhos que, por intermédio de ações, assumem a efemeridade de seus gestos frente à complexidade de fatores sociais e políticos com que deparam. São, em grande maioria, trabalho permeados pela cidade e optam por gestos sutis em detrimento de gestos e intervenções em larga escala com materiais que perdurem no espaço, nos moldes das ações encabeçadas pela land art. Portanto, a leitura e releitura, a configuração e reconfiguração do espaço urbano partem de uma temporalidade e perenidade latentes.

As produções contemporâneas ressaltam essa permeabilidade ao urbano que muitos dos ensaios situacionistas já delineavam. É um caráter distinto de planejamento e descoberta que privilegia a experiência do percurso buscando redescobrir uma sensação tátil frente ao espaço.

A conclusão que aqui se delineia é que um mapeamento das produções contemporâneas passa invariavelmente por assumir e evidenciar aspectos da experiência do percurso urbano em detrimento às nomenclaturas que, porventura, pudessem surgir. Essas mais diversas abordagens parecem encontrar seu ponto de maior relevância, quando privilegiam a tradução nos mais distintos meios da experiência do corpo que se translada, que descobre paulatinamente as idiossincrasias do espaço urbano contemporâneo. Em igual medida, é a crença na efemeridade e na potência desse gesto que parece coligar sua ampla dimensão nos âmbitos não somente artísticos, mas sociais e políticos. O que tal gesto nos incita é a refletir sobre como as práticas do percurso e os deslocamentos sujeitos acabam por tornar-se um referencial determinante à própria concepção e problematização da cidade. Uma forma latente de experiência e registro em que cada uma das intervenções são fragmentos de uma história citadina que está em constante mapeamento e ordenação, assumindo, tal qual aos seus passantes, a condicionante do efêmero e do temporário.

Notas

1 Da genealogia basilar de Francesco Careri em Walkscapes à tese de doutoramento de Jacopo Crivelli Visconti, recentemente publicada sob o título de Novas Derivas passando por uma série de estudiosos franceses como Thierry Davila, Gilles A. Tiberghien e, mais 
recentemente, Nicolas Bourriaud, a definição do caminhante contemporâneo passa invariavelmente pelo entendimento e pela adaptação da deriva como prática.

2 Criado em 1961, sob a liderança de George Maciunas e tendo como membros artistas como Joseph Beuys, Wolf Vostell, Nam June Paik, Bem Vautier e Yoko Ono

3 Guiados pelo absurdo como intenção, os dadaístas e surrealistas eram fortemente iconoclastas e buscavam a destruição do conceito de arte, a antiarte. Os membros da IS, vinculados a essas acepções e almejando uma ruptura radical da antiga estética burguesa, deram continuidade a esses questionamentos em favor de novas expressões.

4 Cabe lembrar que a psicogeografia se definia como um estudo dos efeitos que um determinado ambiente geográfico tinha sobre os sentimentos e sobre o comportamento dos indivíduos. E estabelecia um reconhecimento da cidade por meio de seus edifícios e principais eixos de deslocamento.

\section{Referências}

AMATO, J. A. On foot: a history of walking. New York: New York University Press, 2004.

BARBIER, L. (Org.) Un siècle d'arpenteurs: les figures de la marche. Paris: Museu Picasso, 2000. Catálogo da exposição

BENJAMIN, W. Obras escolhidas. Trad. S. P. Rouanet. São Paulo: Brasiliense, 1985. (Magia e técnica, arte e política, v.I).

Obras escolhidas. Trad. R. R. Torres F. e J. C. M. Barbosa. São Paulo: Brasiliense, 1987. (Rua de mão única, v.II).

Obras escolhidas. Trad. J. C. M. Barbosa e H. A. Baptista. São Paulo: Brasiliense, 1989. (Charles Baudelaire, um lírico no auge do capitalismo, v.III).

BERENSTEIN, P. (Org.) Apologia da deriva, escritos situacionistas sobre a cidade. Rio de Janeiro: Casa da Palavra, 2003.

Elogio aos errantes. Salvador: EDUFBA, 2012.

BISHOP, C. Antagonismo e estética relacional. Tatuí, Recife, n.12, p.109-32, jul.-out. 2011.

BOURRIAUD, N. Estética relacional. São Paulo: Martins Fontes, 2009a.

Pós-produção: como a arte reprograma o mundo contemporâneo. São Paulo: Martins Fontes, 2009b.

Formas de vida: a arte moderna e a invenção de si. Trad. Dorothée de Bruchard. São Paulo: Martins Fontes, 2011 la.

$2011 \mathrm{~b}$.

Radicante: por uma estética da globalização. São Paulo: Martins Fontes,

CARERI, F. Walkscapes: o caminhar como prática estética. São Paulo: GG, 2013.

CERTEAU, M. de. A invenção do cotidiano. Petrópolis: Vozes, 2003. (Artes de fazer, v.1)

FABBRINI, R. A altermodernidade de Nicolas Bourriaud. Tran/Form/Ação, Marília, v.35, n. 3, p. 259-266, set./dez. 2012. 
GOMES, P. Derivações da deriva. 2016. Dissertação (Mestrado em História e Fundamentos da Arquitetura e do Urbanismo) - Faculdade de Arquitetura e Urbanismo, Universidade de São Paulo. São Paulo, 2016.

HATHERLEY, O. Post-Postmodernism?. New Left Review, Issue 59, 2009.

VISCONTI, J. C. Novas derivas. São Paulo: WMF Martins Fontes, 2014.

RESUMO - $\mathrm{O}$ artigo tem como objetivo analisar uma prática artística que, na contemporaneidade, vem ganhando ampla dimensão e recorrência: o deslocamento. As implicações do percurso, sua dimensão plástica e urbanística são motes cruciais a esta análise com base na análise de produções artísticas posteriores à década de 1960. A aproximação apresenta especificidades que tem paulatinamente buscado qualificar o deslocamento urbano nas suas mais diferentes acepções. Nela emergem as principais considerações teóricas sobre as especificidades da caminhada como ato com implicações estéticas e também urbanísticas tendo como base a deriva situacionista e a estética radicante de Nicolas Bourriaud.

PALAVRAS-ChAVE: Arte contemporânea, Forma (estética), Caminhada, Deslocamento, Deriva, Nicolas Bourriad, Forma-trajeto, Urbanismo.

ABSTRACT - This article aims to analyze an artistic practice that, in contemporaneity, has gained a vast extension and recurrence: the act of walking. The implications of one's chosen pathway, its aesthetic and urbanistic dimension, are crucial themes in the analysis, which focuses on the artistic production after the 1960s. This approach presents an inventory of the lexicon that has gradually qualified the act of walking in its various meanings. It is from this glossary that the main theoretical considerations about the specificities of walking as an act with aesthetic implications emerge, based on the situationist dérive of Nicolas Bourriaud's "radicant" aesthetics.

KEYWORDS: Contemporary art, Form (aesthetics), Walking, Displacement, Drift, Nicolas Bourriad, Form-path, Urban theory.

Priscyla Gomes é arquiteta e urbanista pela Faculdade de Arquitetura e Urbanismo da Universidade de São Paulo, e mestre em Arquitetura também pela Universidade de São Paulo. Atualmente, é curadora associada do Instituto Tomie Ohtake.

@ - priscylagomes@gmail.com

Recebido em 25.9.2017 e aceito em 10.10.2017.

${ }^{\text {I }}$ Faculdade de Arquitetura e Urbanismo, Universidade de São Paulo, São Paulo, São Paulo, Brasil. 